\title{
Treatment with anagliptin, a DPP-4 inhibitor, decreases FABP4 concentration in patients with type 2 diabetes mellitus at a high risk for cardiovascular disease who are receiving statin therapy
}

Masato Furuhashi ${ }^{*}$, Ichiro Sakuma², Takeshi Morimoto ${ }^{3}$, Yukimura Higashiura', ${ }^{1}$ Akiko Sakai ${ }^{1}$, Megumi Matsumoto', Mio Sakuma ${ }^{3}$, Michio Shimabukuro ${ }^{4}$, Takashi Nomiyama ${ }^{5}$, Osamu Arasaki ${ }^{6}$, Koichi Node ${ }^{7}$ and Shinichiro Ueda ${ }^{8}$

\begin{abstract}
Background: Fatty acid-binding protein 4 (FABP4) acts as a novel adipokine, and elevated FABP4 concentration is associated with obesity, insulin resistance and atherosclerosis. Dipeptidyl peptidase-4 (DPP-4) inhibitors, a class of antidiabetic drugs, have distinct structures among the drugs, possibly leading to a drug class effect and each drug effect. Sitagliptin, a DPP-4 inhibitor, has been reported to decrease FABP4 concentration in drug-naïve and sulfonylurea-treated patients with type 2 diabetes mellitus. Anagliptin, another DPP-4 inhibitor, was shown to decrease lowdensity lipoprotein cholesterol (LDL-C) level to a greater extent than that by sitagliptin in the Randomized Evaluation of Anagliptin vs. Sitagliptin On low-density lipoproteiN cholesterol in diabetes (REASON) trial.
\end{abstract}

Aim and methods: As a sub-analysis study using data obtained from the REASON trial, we investigated the effects of treatment with anagliptin $(n=148$, male/female: 89/59) and treatment with sitagliptin $(n=159$, male/female: 93/66) for 52 weeks on FABP4 concentration in patients with type 2 diabetes mellitus at a high risk for cardiovascular events who were receiving statin therapy.

Results: The DPP-4 inhibitor had been administered in $82 \%$ of the patients in the anagliptin group and $81 \%$ of the patients in sitagliptin group prior to randomization. Serum FABP4 level was significantly decreased by $7.9 \%$ by treatment with anagliptin $(P=0.049)$ and was not significantly decreased by treatment with sitagliptin $(P=0.660)$. Change in FABP4 level was independently associated with basal FABP4 level and changes in waist circumference and creatinine after adjustment of age, sex and the treatment group.

Conclusion: Anagliptin decreases serum FABP4 concentration independent of change in hemoglobin A1C or LDL-C in patients with type 2 diabetes mellitus and dyslipidemia who are on statin therapy.

\footnotetext{
${ }^{*}$ Correspondence: furuhasi@sapmed.ac.jp

${ }^{1}$ Department of Cardiovascular, Renal and Metabolic Medicine,

Sapporo Medical University School of Medicine, South 1, West 16, Sapporo 060-8543, Japan

Full list of author information is available at the end of the article
}

c) The Author(s) 2020. This article is licensed under a Creative Commons Attribution 4.0 International License, which permits use, sharing, adaptation, distribution and reproduction in any medium or format, as long as you give appropriate credit to the original author(s) and the source, provide a link to the Creative Commons licence, and indicate if changes were made. The images or other third party material in this article are included in the article's Creative Commons licence, unless indicated otherwise in a credit line to the material. If material is not included in the article's Creative Commons licence and your intended use is not permitted by statutory regulation or exceeds the permitted use, you will need to obtain permission directly from the copyright holder. To view a copy of this licence, visit http://creativeco mmons.org/licenses/by/4.0/. The Creative Commons Public Domain Dedication waiver (http://creativecommons.org/publicdomain/ zero/1.0/) applies to the data made available in this article, unless otherwise stated in a credit line to the data. 
Trial registration ClinicalTrials.gov number NCT02330406. Registered January 5, 2015, https://clinicaltrials.gov/ct2/ show/NCT02330406

Keywords: Anagliptin, Sitagliptin, Dipeptidyl peptidase-4 inhibitor, Fatty acid-binding protein

\section{Background}

Fatty acid-binding proteins (FABPs) are about $14-15-\mathrm{kDa}$ predominantly cytosolic proteins that can reversibly bind long-chain fatty acids with high affinity and facilitate the transport of lipids to specific compartments in the cell [1, 2]. Among FABPs, fatty acid binding protein 4 (FABP4), also referred to as adipocyte FABP or aP2, is mainly expressed in adipose tissue, including adipocytes and macrophages, and plays an important role in the development of insulin resistance and atherosclerosis [3-5]. Chemical inhibition of FABP4 by a small molecule inhibitor could be a novel therapeutic strategy against insulin resistance, diabetes mellitus and atherosclerosis [6]. Recent studies have also demonstrated that neutralization of secreted FABP4 with an antibody to FABP4 could be a feasible approach for treatment of insulin resistance, type 2 diabetes mellitus, vascular injury and atherosclerosis [7-9].

FABP4 is secreted from adipocytes via a non-classical secretion pathway in association with lipolysis $[7,10]$ despite the lack of signal peptides [2] and acts as an adipokine for the development of insulin resistance, atherosclerosis and vascular remodeling $[7,8,11]$. Elevated serum concentration of FABP4 is associated with obesity, insulin resistance, hypertension, dyslipidemia, atherosclerosis, renal dysfunction, purine metabolism, heart failure and cardiovascular events [12-19]. Recent studies have also demonstrated modulation of FABP4 concentration by therapeutic drugs for hypertension, dyslipidemia and diabetes mellitus [20-26].

Dipeptidyl peptidase-4 (DPP-4) inhibitors, a class of antidiabetic drugs, have become standard drugs to improve hemoglobin A1c (HbA1c) levels in patients with type 2 diabetes mellitus [27]. It has been shown that DPP-4 inhibitors reduce intima media thickness, a marker of atherosclerosis [28, 29]. However, improvement of cardiovascular outcomes by adding DPP-4 inhibitors to usual care in patients with diabetes mellitus and cardiovascular diseases has not yet been proved [30-34]. DPP-4 inhibitors have distinct structures among the drugs [35]. Therefore, there might be an effect of each drug as well as a class effect of DPP-4 inhibitors. As a possible drug effect, anagliptin, a DPP-4 inhibitor, was reported to reduce low-density lipoprotein cholesterol (LDL-C) for 12-24 weeks regardless of the use of statins [36, 37]. Furthermore, treatment with anagliptin for 52 weeks was shown to be associated with a greater reduction in serum LDL-C levels compared to treatment with sitagliptin in patients with type 2 diabetes mellitus at high risk for cardiovascular events and with an LDL-C level $>100 \mathrm{mg} / \mathrm{dL}$ who were receiving statin treatment [38].

On the other hand, a monotherapy with sitagliptin and combination therapy with sitagliptin and a sulfonylurea agent for 12 weeks significantly decreased FABP4 concentration in patients with type 2 diabetes [23]. To reveal whether it is each drug effect or a drug class effect of DPP-4 inhibitors, we investigated the effects of treatment with the DPP-4 inhibitors anagliptin and sitagliptin for a relatively long period on FABP4 level in patients with type 2 diabetes mellitus at a high risk for cardiovascular events who were on statin therapy as a real-world setting.

\section{Methods}

\section{Study patients}

Study patients were retrieved from the Randomized Evaluation of Anagliptin vs. Sitagliptin On low-density lipoprotein cholesterol in diabetes (REASON) trial [38]. The detailed design including criteria for inclusion and exclusion in the REASON trial were previously reported $[38,39]$. In brief, the trial was a multicenter, randomized, open-label, parallel-group design that investigated the effects of DPP-4 inhibitors, anagliptin (100 mg, twice daily) and sitagliptin (50 mg once daily), on reduction in LDL-C in adult patients with type 2 diabetes mellitus at high risk for cardiovascular events and with LDL-C levels of $>100 \mathrm{mg} / \mathrm{dL}$ who were receiving treatment with a statin. The recruited patients had previously documented atherosclerotic lesions in the coronary, intracranial, carotid, or other peripheral arteries. Randomization was centrally done with a web-based system using an algorithm balanced for sex, body mass index, hospitals, use of DPP-4 inhibitors prior to randomization, and levels of HbA1c and LDL-C. Antidiabetic drugs other than DPP-4 inhibitors at the beginning of the trial were concomitantly administered, and the original antidiabetic drugs were not replaced. During the period of the trial, antidiabetic and anti-dyslipidemia drugs were not added, and their dosages were not changed except for the dose of insulin.

The REASON trial was registered on Clinicaltrials.gov (NCT02330406) and was conducted in accordance with the Declaration of Helsinki and the Ethical Guidelines for Medical and Health Research Involving Human Subjects 
in Japan. The protocol and consent forms were approved by the institutional review boards at the University of the Ryukyus (No. 731) and each participating center. Written informed consent was obtained from all enrolled patients prior to randomization. In the first report of the REASON trial, anagliptin was reported to decrease LDL-C level to a greater extent than sitagliptin [38]. Sub-analysis studies using stored serum samples were planned in the protocol and were conducted according to the decision of the steering committee. The present study was one of the sub-analysis studies, and the effects of anagliptin and sitagliptin on FABP4 concentration were investigated. Among 313 patients who were enrolled in and completed the REASON trial, a total of 307 patients who were treated with anagliptin $(\mathrm{n}=148$; male/female: $89 / 59)$ or sitagliptin ( $\mathrm{n}=159$; male/female: 93/66) for 52 weeks and for whom serum samples were stored were included in the present study.

\section{Measurements}

Body mass index (BMI) calculated as body weight in kilograms divided by height in meters squared, waist circumference, past medical history, smoking status, alcohol consumption and use of concomitant drugs were evaluated at baseline. BMI was also checked at 52 weeks. Aspartate transaminase (AST), alanine aminotransferase, $\gamma$-glutamyl transpeptidase ( $\gamma \mathrm{GTP})$, blood urea nitrogen, creatinine and fasting glucose were measured in each participating center at baseline and at 52 weeks. Estimated glomerular filtration rate (eGFR) was calculated from data for serum creatinine, age and sex using the following equation: eGFR $\left(\mathrm{mL} / \mathrm{min} / 1.73 \mathrm{~m}^{2}\right)=194 \times$ serum creatinine $^{(-1.094)} \times$ age $^{(-0.287)} \times 0.739$ (if female) [40]. Hemoglobin A1c (HbA1c) presented as the National Glycohemoglobin Standardization Program (NGSP) equivalent value, LDL-C measured by the direct method, total cholesterol, high-density lipoprotein cholesterol (HDL$\mathrm{C})$, triglycerides and insulin were analyzed at baseline and at 52 weeks in a core laboratory (SRL Inc., Tokyo, Japan). FABP4 concentration was measured using a commercially available enzyme-linked immunosorbent assay kit for FABP4 (BioVendor R\&D, Czech Republic). The accuracy, precision and reproducibility of the kit have been described previously [12].

\section{Statistical analysis}

Continuous variables were expressed as means with standard deviation (SD), means with standard error (SE) or medians with interquartile ranges. Categorical variables were expressed as the number with percentages and were compared between the treatment groups by the chisquared test or Fisher's exact test. Changes in parameters from baseline to 52 weeks in the groups were compared using the paired t-test, and differences in changes between the two treatment groups were analyzed by using the two-sample t-test. Correlations between two continuous variables were analyzed by using Pearson's correlation coefficient. Multivariate linear regression models were constructed to explore independent parameters of change in FABP4 level. Age, sex, treatment group as well as variables with significant correlations determined by Pearson's coefficient were incorporated in the models. The relationships were expressed with unstandardized regression coefficient, $\mathrm{SE}$ of regression coefficient and standardized regression coefficient $(\beta)$. All statistical analyses were performed at an independent data center (Institute for Clinical Effectiveness, Kyoto, Japan) by study statisticians using JMP 13.1 (SAS Institute Inc, Cary, NC) and SAS 9.4 (SAS Institute Inc, Cary, NC). All $\mathrm{P}$ values were two-sided, and $\mathrm{P}<0.05$ was considered statistically significant.

\section{Results}

Characteristics of the patients at baseline

Baseline characteristics of the patients treated with anagliptin or sitagliptin are shown in Table 1. At baseline, $73-79 \%$ of the patients had hypertension and $45-46 \%$ of the patients had a previous history of coronary artery disease. A DPP-4 inhibitor was being administrated to $82 \%$ of the patients in the anagliptin group and $81 \%$ of the patients in the sitagliptin group prior to randomization. There was no significant difference between the anagliptin and sitagliptin treatment groups in the prevalence of habits of smoking and alcohol drinking, diagnosis including hypertension, coronary artery disease and stroke, and medications. There was also no significant difference in metabolic parameters except for BMI at baseline between the anagliptin and sitagliptin groups (Table 1).

\section{Changes in metabolic parameters from baseline to 52 weeks}

Treatment with anagliptin for 52 weeks significantly increased creatinine level and decreased BMI and levels of eGFR, total cholesterol and LDL-C (Table 2). On the other hand, treatment with sitagliptin for 52 weeks significantly increased AST, total cholesterol, HDL-C, fasting glucose and HbA1c. There were significant differences in changes in parameters including AST, total cholesterol, LDL-C and HDL-C from baseline to 52 weeks between the anagliptin and sitagliptin groups (Table 2). There was no significant difference in basal FABP4 levels in the anagliptin and sitagliptin groups, and serum FABP4 level was significantly decreased by $7.9 \%$ by treatment with anagliptin $(27.8 \pm 19.1$ vs. $25.6 \pm 15.5 \mathrm{ng} / \mathrm{mL}$, mean \pm SE, $\mathrm{P}=0.049$ ) and was not significantly decreased by treatment with sitagliptin $(26.9 \pm 15.5$ vs. $26.5 \pm 17.9 \mathrm{ng} /$ 
Table 1 Background of the patients with type 2 diabetes mellitus $(n=307)$

\begin{tabular}{|c|c|c|c|}
\hline & Anagliptin & Sitagliptin & $P$ \\
\hline$n(M / F)$ & $148(89 / 59)$ & $159(93 / 66)$ & 0.77 \\
\hline Age (years) & $68 \pm 9$ & $68 \pm 9$ & 0.91 \\
\hline Body mass index & $26.7 \pm 3.9$ & $25.8 \pm 3.6$ & 0.04 \\
\hline Waist circumference (cm) & $94.2 \pm 11.1$ & $92.7 \pm 9.8$ & 0.24 \\
\hline Smoking habit & $71(48)$ & $92(58)$ & 0.08 \\
\hline Alcohol drinking habit & $58(39)$ & $67(42)$ & 0.60 \\
\hline \multicolumn{4}{|l|}{ Diagnosis } \\
\hline Hypertension & $117(79)$ & $116(73)$ & 0.21 \\
\hline Coronary artery disease & $68(46)$ & $71(45)$ & 0.82 \\
\hline Stroke & $22(15)$ & $24(15)$ & 0.96 \\
\hline \multicolumn{4}{|l|}{ Medication } \\
\hline Dipeptidyl peptidase-4 inhibitor ${ }^{a}$ & $122(82)$ & $128(81)$ & 0.66 \\
\hline Biguanide & $74(50)$ & $71(45)$ & 0.35 \\
\hline Thiazolidinedione & $22(15)$ & $29(18)$ & 0.43 \\
\hline a glucosidase inhibitor & $19(13)$ & $27(17)$ & 0.31 \\
\hline Sulfonylurea & $41(28)$ & $32(20)$ & 0.12 \\
\hline Glinide & $7(5)$ & $2(1)$ & 0.09 \\
\hline $\begin{array}{l}\text { Sodium-glucose cotransporter } 2 \\
\text { inhibitor }\end{array}$ & $25(17)$ & $16(10)$ & 0.08 \\
\hline Insulin & $12(8)$ & $13(8)$ & 0.98 \\
\hline Statin & $148(100)$ & $159(100)$ & - \\
\hline Strong statin ${ }^{b}$ & $118(80)$ & $121(76)$ & 0.44 \\
\hline Ezetimibe & $16(11)$ & $11(7)$ & 0.23 \\
\hline Fibrate & $9(6)$ & $7(4)$ & 0.51 \\
\hline Eicosapentaenoic acid & $16(11)$ & $13(8)$ & 0.43 \\
\hline Angiotensin II receptor blocker & $75(51)$ & $80(50)$ & 0.95 \\
\hline $\begin{array}{l}\text { Angiotensin-converting enzyme } \\
\text { inhibitor }\end{array}$ & $18(12)$ & $10(6)$ & 0.07 \\
\hline Calcium channel blocker & $72(49)$ & $68(43)$ & 0.30 \\
\hline$\beta$ blocker & $35(24)$ & $38(24)$ & 0.96 \\
\hline Diuretic & $24(16)$ & $20(13)$ & 0.36 \\
\hline Mineralocorticoid receptor antagonist & $6(4)$ & $6(4)$ & 0.90 \\
\hline
\end{tabular}

Variables are expressed as number (\%), mean \pm SD or medians (interquartile ranges)

a The use before the study

b Indicates atorvastatin, rosuvastatin and pitavastatin

$\mathrm{mL}$, mean $\pm \mathrm{SE}, \mathrm{P}=0.660$ ) (Fig. 1a). No significant difference in change in FABP4 levels was found between the anagliptin and sitagliptin groups $(-2.1 \pm 13.4$ vs. $-0.4 \pm 11.5 \mathrm{ng} / \mathrm{mL}$, mean $\pm \mathrm{SE}, \mathrm{P}=0.212$ ) (Fig. 1b).

\section{Parameters associated with change in FABP4 level}

As shown in Table 3, in all of the patients, change in FABP4 level was negatively correlated with FABP4 concentration at baseline (Fig. 2a) and changes in $\gamma$ GTP and eGFR and was positively correlated with changes in waist circumference (Fig. 2b), blood urea nitrogen and creatinine (Fig. 2c). No significant correlation of change in FABP4 with change in total cholesterol, LDL-C, HDL$\mathrm{C}$, triglycerides, fasting glucose, insulin or HbA1c was found (Table 3). Similar significant correlations of change in FABP4 level with the parameters except for change in waist circumference, that in $\gamma$ GTP and that in eGFR were found when the treatment groups were separately analyzed.

Multivariate linear regression models using age, sex, treatment group, FABP4 level at baseline and changes in waist circumference and creatinine as possible independent parameters showed that basal FABP4 level, change in waist circumference and change in creatinine were independent predictors of change in FABP4 level after adjustment of age, sex and treatment group $\left(R^{2}=0.294\right)$ (Table 4).

\section{Discussion \\ Main findings}

The present study demonstrated that anagliptin, which has been reported to decrease LDL-C level [36-38], significantly reduced FABP4 concentration independent of change in HbA1c or LDL-C in patients with type 2 diabetes mellitus, dyslipidemia and existing atherosclerotic vascular lesions who were being prescribed statins. A statin was concomitantly used in all of the recruited patients, and angiotensin II receptor blockers and eicosapentaenoic acid were also administered in $50-51 \%$ and $8-11 \%$ of the patients, respectively. Those concomitant drugs have been shown to decrease FABP4 concentration [20-22]. It has been reported that treatment with sitagliptin alone and/or in combination with sulfonylurea decreases serum FABP4 level in patients with type 2 diabetes mellitus [23]. In the present study, more than $80 \%$ of the patients were pretreated with a DPP-4 inhibitor. The use of several kinds of pretreatment and concomitant drugs, which may modulate FABP4 concentration, is a possible reason for the lack of reduction in FABP4 level by treatment with sitagliptin in the present study. Reduction of FABP4 levels could be a class effect of DPP-4 inhibitors, though there had been no direct comparison of the effects of DPP-4 inhibitors on FABP4 levels. Anagliptin may be able to decrease serum FABP4 concentrations to a greater extent than sitagliptin in patients with type 2 diabetes mellitus and dyslipidemia who are on statin therapy.

\section{Possible mechanisms of reduction in FABP4 concentration by anagliptin}

DPP-4 inhibitors have distinct structures among the drugs and include peptidomimetic and non-peptidomimetic agents [35], possibly leading to a drug class effect and each drug effect. Furthermore, DPP-4 inhibitors have been categorized into three classes of 
Table 2 Characteristics of the patients treated with sitagliptin or anagliptin for 52 weeks $(n=307)$

\begin{tabular}{|c|c|c|c|c|c|c|c|}
\hline & \multicolumn{2}{|c|}{ Anagliptin $(n=148)$} & \multirow[t]{2}{*}{$P$} & \multicolumn{2}{|c|}{ Sitagliptin $(n=159)$} & \multirow[t]{2}{*}{$P$} & \multirow[t]{2}{*}{$P^{a}$} \\
\hline & Baseline & 52 weeks & & Baseline & 52 weeks & & \\
\hline Body mass index & $26.7 \pm 3.9$ & $26.5 \pm 4.1$ & 0.04 & $25.8 \pm 3.6$ & $25.8 \pm 3.8$ & 0.92 & 0.12 \\
\hline Waist circumference $(\mathrm{cm})$ & $94.2 \pm 11.1$ & $93.6 \pm 10.9$ & 0.30 & $92.7 \pm 9.8$ & $92.4 \pm 9.6$ & 0.56 & 0.69 \\
\hline AST (IU/L) & $23(18-30)$ & $23(18-29)$ & 0.14 & $20(18-25)$ & $21(18-27)$ & 0.02 & $<0.01$ \\
\hline ALT (IU/L) & $23(17-34)$ & $22(14-33)$ & 0.12 & $18(15-26)$ & $19(14-26)$ & 0.42 & 0.08 \\
\hline үGTP (IU/L) & $30(18-46)$ & $27(19-42)$ & 0.16 & $24(18-35)$ & $24(18-36)$ & 0.12 & 0.07 \\
\hline Blood urea nitrogen $(\mathrm{mg} / \mathrm{dL})$ & $16.7 \pm 6.0$ & $16.8 \pm 5.3$ & 0.89 & $17.1 \pm 5.6$ & $17.5 \pm 5.5$ & 0.30 & 0.51 \\
\hline Creatinine $(\mathrm{mg} / \mathrm{dL})$ & $0.84 \pm 0.27$ & $0.86 \pm 0.29$ & 0.04 & $0.86 \pm 0.29$ & $0.87 \pm 0.29$ & 0.17 & 0.34 \\
\hline eGFR (mL/min/1.73 m²) & $68.9 \pm 20.7$ & $66.8 \pm 20.6$ & 0.02 & $66.9 \pm 18.5$ & $65.7 \pm 18.4$ & 0.06 & 0.44 \\
\hline Total cholesterol (mg/dL) & $190 \pm 30$ & $186 \pm 28$ & 0.02 & $186 \pm 29$ & $191 \pm 27$ & 0.01 & $<0.01$ \\
\hline LDL cholesterol (mg/dL) & $112 \pm 22$ & $108 \pm 22$ & 0.01 & $110 \pm 22$ & $112 \pm 21$ & 0.15 & $<0.01$ \\
\hline HDL cholesterol (mg/dL) & $54 \pm 14$ & $53 \pm 13$ & 0.43 & $55 \pm 13$ & $56 \pm 13$ & $<0.01$ & 0.01 \\
\hline Triglycerides (mg/dL) & $136(98-190)$ & $134(97-185)$ & 0.80 & $114(80-158)$ & $110(82-160)$ & 0.22 & 0.55 \\
\hline Fasting glucose (mg/dL) & $143 \pm 42$ & $147 \pm 48$ & 0.18 & $140 \pm 39$ & $146 \pm 44$ & $<0.01$ & 0.47 \\
\hline Insulin ( $\mu \mathrm{U} / \mathrm{mL})$ & $8.0(5.7-12.0)$ & $8.5(5.3-13.3)$ & 0.51 & $6.9(4.5-11.0)$ & $7.1(4.7-11.5)$ & 0.54 & 0.39 \\
\hline $\mathrm{HbA1c}(\%)$ & $7.1 \pm 0.8$ & $7.1 \pm 0.9$ & 0.71 & $6.9 \pm 0.7$ & $7.0 \pm 0.9$ & 0.04 & 0.28 \\
\hline
\end{tabular}

Variables are expressed as mean \pm SD or medians (interquartile ranges)

AST aspartate transaminase, ALT alanine transaminase, eGFR estimated glomerular filtration rate, $\gamma G T P \gamma$-glutamyl transpeptidase

a For group difference in absolute change from baseline to 52 weeks

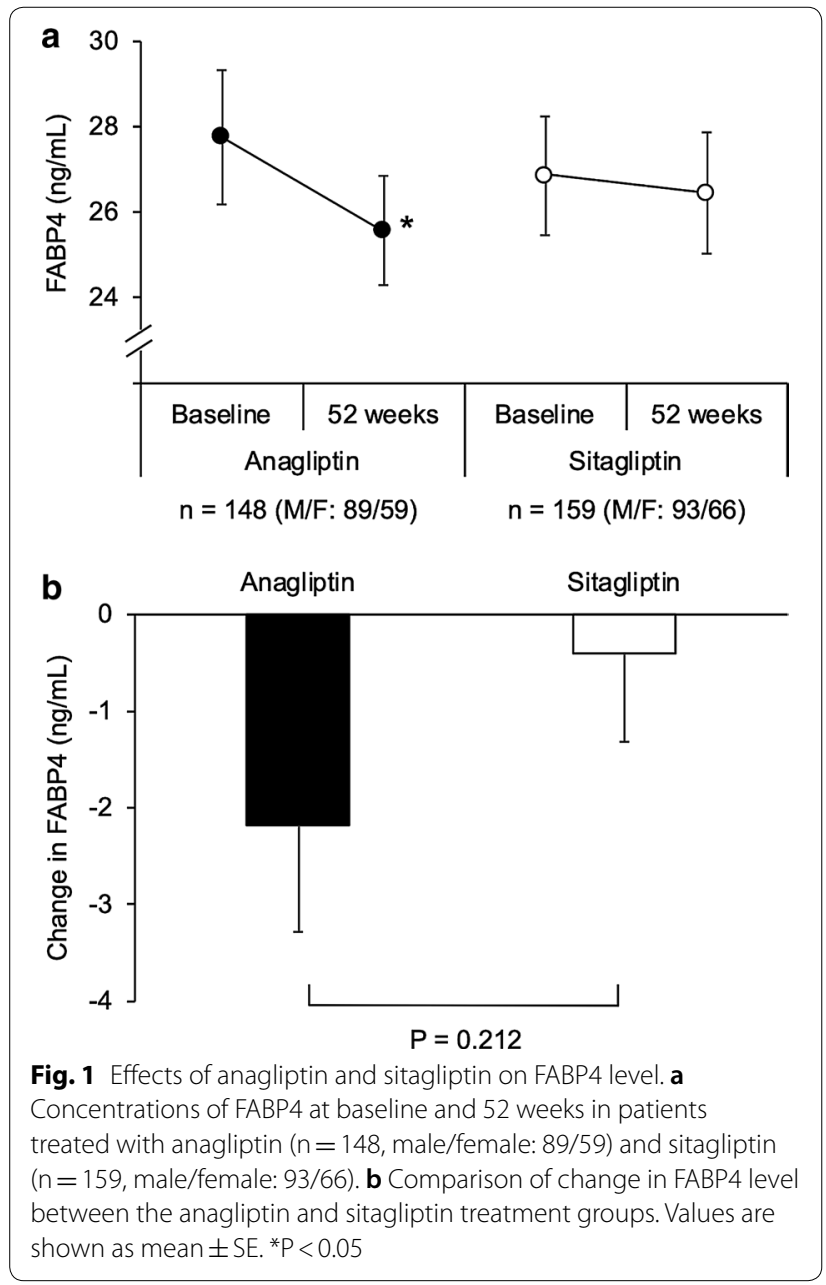

binding pocket on the basis of their binding subsites $[41,42]$. The selectivity, specificity and extent of action of each drug may cause specific and pleiotropic effects. However, little is known about the differences in those effects among different types of DPP-4 inhibitors.

A possible drug effect of anagliptin is the reduction of LDL-C [36-38]. Experimental studies showed that anagliptin reduced cholesterol synthesis due to downregulation by sterol regulatory element-binding protein 2 in the liver [43] and inhibited absorption of cholesterol in the small intestine [44], leading to the reduction of LDL-C level. In a human study using a small number of drug-naïve patients with type 2 diabetes and LDL-C $>120 \mathrm{mg} / \mathrm{dL}(\mathrm{n}=30)$, anagliptin significantly decreased a cholesterol synthesis marker, lathosterol, without affecting cholesterol absorption markers including campesterol, sitosterol and cholestanol [45]. Furthermore, a previous sub-analysis using data from the REASON trial demonstrated that anagliptin reduced LDL-C level by suppressing excess cholesterol synthesis even when it was used in combination with statin therapy [46]. Taken together, these findings suggest that anagliptin exerts a hepatoprotective effect beyond its glycemic-lowering action. However, no association of change in FABP4 level with change in LDL-C level was found in the present study. A distinct mechanism by which FABP4 level is decreased by anagliptin needs to be addressed in the future. 
Table 3 Correlation analysis for $\triangle$ FABP4

\begin{tabular}{|c|c|c|c|c|c|c|}
\hline & \multicolumn{2}{|c|}{ Total $(n=307)$} & \multicolumn{2}{|c|}{ Anagliptin $(n=148)$} & \multicolumn{2}{|c|}{ Sitagliptin $(n=159)$} \\
\hline & $r$ & $\mathbf{P}$ & $r$ & $\mathbf{P}$ & $r$ & $\mathbf{P}$ \\
\hline Age at baseline & -0.04 & 0.47 & -0.03 & 0.73 & -0.06 & 0.49 \\
\hline FABP4 at baseline & -0.46 & $<0.01$ & -0.59 & $<0.01$ & -0.30 & $<0.01$ \\
\hline$\Delta$ body mass index & 0.05 & 0.41 & -0.09 & 0.26 & 0.20 & 0.01 \\
\hline$\Delta$ waist circumference & 0.15 & 0.01 & 0.00 & 0.96 & 0.33 & $<0.01$ \\
\hline$\triangle \mathrm{AST}$ & -0.10 & 0.07 & -0.02 & 0.83 & -0.21 & 0.01 \\
\hline$\triangle \mathrm{ALT}$ & -0.06 & 0.26 & -0.05 & 0.56 & -0.11 & 0.19 \\
\hline$\Delta \gamma \mathrm{GTP}$ & -0.14 & $<0.01$ & 0.01 & 0.89 & -0.23 & $<0.01$ \\
\hline$\Delta$ blood urea nitrogen & 0.21 & $<0.01$ & 0.20 & 0.01 & 0.21 & 0.01 \\
\hline$\Delta$ creatinine & 0.28 & $<0.01$ & 0.33 & $<0.01$ & 0.24 & $<0.01$ \\
\hline$\triangle \mathrm{eGFR}$ & -0.18 & $<0.01$ & -0.20 & 0.01 & -0.15 & 0.06 \\
\hline$\Delta$ total cholesterol & 0.04 & 0.47 & 0.02 & 0.80 & 0.03 & 0.66 \\
\hline$\triangle \mathrm{LDL}$ cholesterol & 0.05 & 0.42 & 0.00 & 0.97 & 0.08 & 0.35 \\
\hline$\triangle \mathrm{HDL}$ cholesterol & -0.05 & 0.41 & -0.15 & 0.07 & 0.04 & 0.59 \\
\hline$\Delta$ triglycerides & 0.04 & 0.43 & 0.14 & 0.08 & -0.08 & 0.29 \\
\hline$\Delta$ fasting glucose & 0.01 & 0.88 & 0.01 & 0.87 & 0.00 & 0.96 \\
\hline$\Delta$ insulin & 0.05 & 0.40 & 0.00 & 0.97 & 0.15 & 0.06 \\
\hline$\triangle \mathrm{HbA} 1 \mathrm{c}$ & 0.02 & 0.74 & -0.01 & 0.87 & 0.05 & 0.54 \\
\hline
\end{tabular}

$\triangle$, change calculated as parameter in 52 weeks minus that in baseline

AST aspartate transaminase, $A L T$ alanine transaminase, eGFR estimated glomerular filtration rate, $\gamma G T P \gamma$-glutamyl transpeptidase

\section{Possible drug class effect of DPP-4 inhibitors on FABP4 concentration}

A previous study demonstrated that the mechanism of the decrease in FABP4 level by a DPP-4 inhibitor is, at least in part, via reduction in the expression and consecutive secretion of FABP4 in adipocytes by direct inhibition of soluble DPP-4 as an adipokine [23]. It has also been reported that postprandial hyperglycemia and fluctuation of glucose level, which may cause sympathetic nerve activation [47], are improved by DPP-4 inhibitors [48]. Since FABP4 is secreted from adipocytes in association with lipolysis [7, 10], DPP4 inhibitors may decrease FABP4 concentration by inhibiting FABP4 secretion from adipocytes in association with sympathetic tone-mediated lipolysis. However, glucose fluctuation assessed by 1,5-anhydroglucitol level and/or continuous glucose monitoring was not investigated in the present study. DPP4 inhibitors have also been shown to suppress inflammatory responses through activation of NACHT, LRR and PYD domainscontaining protein 3 (NLRP3) inflammasome and c-jun $\mathrm{N}$-terminal kinase $[49,50]$ and to decrease levels of tumor necrosis factor and interleukin 6 [51,52], which are known to increase lipolysis in adipocytes [53]. This could be another indirect mechanism of the decrease in FABP4, though those factors were not evaluated in the present study.

\section{Change in FABP4 level}

In all of the patients, change in FABP4 level was independently associated with basal FABP4 level and changes in waist circumference and creatinine after adjustment of age, sex and the treatment group (Table 4). There was no significant difference between basal FABP4 levels in the anagliptin and sitagliptin treatment groups. It has been reported that FABP4 level is independently associated with adiposity $[12,13]$ and a decline of renal function $[13,17]$. In the present study, treatment with anagliptin, but not treatment with sitagliptin, significantly decreased BMI as an index of adiposity even in concomitant with a significant increase in creatine level, suggesting that reduction of adiposity by anagliptin, but not sitagliptin, leads to a decrease in FABP4 level.

\section{Limitations}

First, no washout of DPP4 inhibitors before the beginning of trial was performed. Pretreatment with DPP-4 inhibitors may have affected the FABP4 concentration. Second, most of the study subjects were being treated at baseline with several drugs including antidiabetic drugs [23-26], statins [20], angiotensin II receptor blockers [21] and omega-3 fatty acid ethyl esters [22], which have been reported to affect circulating FABP4 concentration. Therefore, such drugs might have modulated 

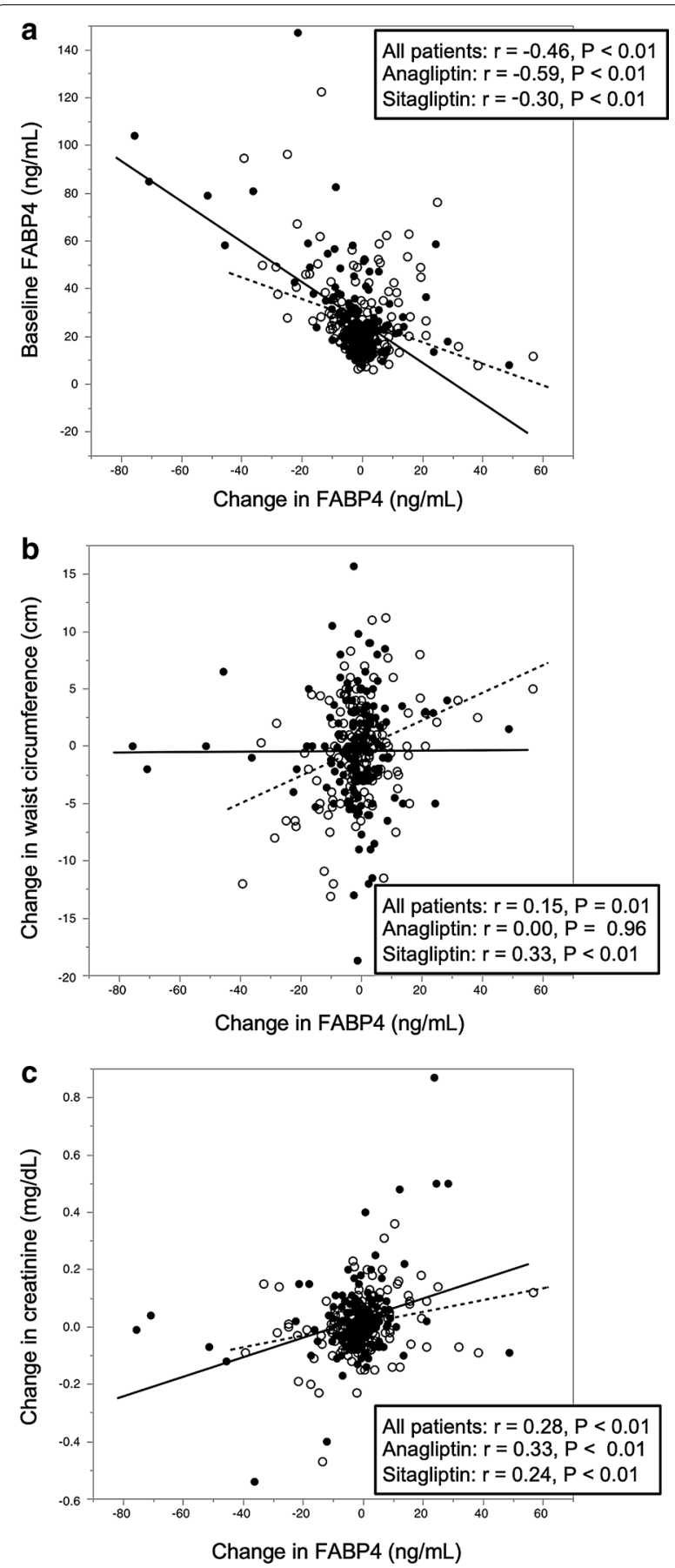

Fig. 2 Correlations of change in FABP4 level with parameters. a-c Fatty acid-binding protein 4 (FABP4) level at baseline (a), change in waist circumference (b) and change in creatinine level (c) were plotted against change in FABP4 level in each subject $(n=307)$. Closed circles and solid regression line: anagliptin treatment group $(n=148)$, open circles and broken regression line: sitagliptin treatment group $(n=159)$
Table 4 Multivariate regression analysis for $\triangle$ FABP4

\begin{tabular}{lcccr}
\hline & $\begin{array}{l}\text { Regression } \\
\text { coefficient }\end{array}$ & SE & $\begin{array}{l}\text { Standardized } \\
\text { regression } \\
\text { coefficient }(\boldsymbol{\beta})\end{array}$ & $\boldsymbol{P}$ \\
\hline Age & 0.01 & 0.07 & 0.01 & 0.91 \\
Sex (male) & -1.82 & 1.30 & -0.07 & 0.16 \\
DPP-4i (anagliptin) & -1.81 & 1.23 & -0.07 & 0.14 \\
FABP4 at baseline & -0.31 & 0.03 & -0.45 & $<0.01$ \\
$\begin{array}{l}\triangle \text { Waist circumfer- } \\
\text { ence }\end{array}$ & 0.29 & 0.14 & 0.10 & 0.04 \\
$\triangle$ Creatinine & 26.1 & 5.27 & 0.25 & $<0.01$ \\
\hline
\end{tabular}

$\mathrm{R}^{2}=0.294$

$\Delta$, change calculated as parameter in 52 weeks minus that in baseline $D P P-4 i$ dipeptidyl peptidase-4 inhibitor, eGFR estimated glomerular filtration rate, FABP4 fatty acid-binding protein 4

the change in FABP4 level. However, randomized allocation should balance these drugs between groups and minimize the effects. Third, the present study lacked a placebo control group. Interventional studies using larger number of subjects and a placebo-control design are necessary for determining the impact of DPP-4 inhibitor treatment on circulating FABP4 level and the relationship between change in FABP4 level and clinical benefit of DPP-4 inhibitors. Lastly, the impact of a $7.9 \%$ reduction of FABP4 level by anagliptin is unclear, though previous studies using experimental models showed metabolic and cardiovascular effects of circulating FABP4 and neutralizing antibody of FABP4 $[7,8$, $11,54]$.

\section{Conclusion}

Anagliptin decreases FABP4 concentration independent of change in hemoglobin A1c or LDL-C in patients with type 2 diabetes mellitus at a high risk for cardiovascular events who are on statin therapy. This study provides additional evidence for the importance of careful selection of the drug regimen for patients with diabetes mellitus and other risk factors in order to prevent cardiovascular events. Reduction of FABP4 level as a possible class and pleiotropic effect of DPP-4 inhibitors might be beneficial for patients with metabolic and cardiovascular diseases. A further understanding of the mechanisms by which FABP4 level is changed by pharmacological modulation may enable the development of new therapeutic strategies for cardiovascular and metabolic diseases.

\section{Abbreviations}

AST: Aspartate transaminase; BMI: Body mass index; DPP-4: Dipeptidyl peptidase 4; eGFR: Estimated glomerular filtration rate; FABP: Fatty acid-binding protein; $\gamma$ GTP: $\gamma$-glutamyl transpeptidase; HbA1c: Hemoglobin A1 c; HDL-C: 
High-density lipoprotein cholesterol; LDL-C: Low-density lipoprotein cholesterol; SD: Standard deviation; SE: Standard error.

\section{Acknowledgements}

The authors are grateful to Dr. Tetsuji Miura for valuable discussion and Ms. Kaori Yamamoto, Ms. Makiko Ohtorii, Ms. Ai Sunagawa, Ms. Sachiko Kitamura, Ms. Hirono Saito and Ms. Saeko Nagano in the Institute for Clinical Effectiveness for data management and statistical analyses.

\section{Authors' contributions}

All authors made substantial contributions to the conception, design, and acquisition and interpretation of data. TM and MSa carried out the statistical analyses. MF prepared the first draft of the manuscript. All authors participated in reviewing the manuscript and take full responsibility for its content. All authors read and approved the final manuscript.

\section{Funding}

The REASON trial was funded by Kowa Company, Ltd. M.F. has been supported by grants from Japan Society for the Promotion of Science (JSPS), SENSHIN Medical Research Foundation and Terumo Life Science Foundation.

\section{Availability of data and materials}

The datasets analyzed during the current study are available from the corresponding author on reasonable request (furuhasi@sapmed.ac.jp).

\section{Ethics approval and consent to participate}

The ethical committees of the participating institutions approved the study protocol. Written informed consent for participation in the study was obtained from all the subjects.

\section{Consent for publication}

All authors have read and approved the submission of the manuscript. The manuscript has not been published and is not being considered for publication elsewhere, in whole or in part, in any language. If the manuscript is accepted, we approve it for publication in Cardiovascular Diabetology.

\section{Competing interests}

MF. reports non-purpose research grants from Astellas, Mitsubishi Tanabe, Sanwa Kagaku Kenkyusho and MediciNova; lecturer's fees from Mitsubishi Tanabe, Kowa, Mochida, Daiichi Sankyo, Novartis, Boehringer Ingelheim, MSD, Sanwa Kagaku Kenkyusho, Takeda, Astellas, Sanofi and AstraZeneca. I.S. reports research grants from Public Health Research Foundation, Kowa, National Cerebral and Cardiovascular Center and Medical Informatics Study Group; non-purpose research grants from Public Health Research Foundation, Eastep, Nexis, Takeda, Daiichi Sankyo, Beohringer Ingelheim, AstraZeneca, MSD, Amgen, Astellas, Sanofi, Fuji and Novartis; lecturer's fees from AstraZeneca, Takeda, Bayer, Pfizer, Bristol-Myers Squibb, Boehringer Ingelheim, MSD, Kyowa Hakko Kirin, Daiichi Sankyo, Novartis, Sanofi, Kowa, Shionogi, Kissei, Astellas, Amgen, Ono, Otsuka, Novonordisk, Mochida, Teijin, Sysmex, Nipro, Kyorin, Fuji and Sumitomo Dainippon; advisory board for Public Health Research Foundation, Kowa, Tanabe, Kyowa Hakko Kirin and Bristol-Myers Squibb, Sysmex. T.M. reports lecturer's fees from Bayer, Daiichi Sankyo, Japan Lifeline, Kyocera, Mitsubishi Tanabe, Novartis, and Toray; manuscript fees from Bristol-Myers Squibb and Kowa; advisory boards for Asahi Kasei, Boston Scientific, and Bristol-Myers Squibb. Y.H., A.S. M.M. and M.Sa. declares no conflicts of interest. M.Sh. reports research grants from AstraZeneca, Ono, and Sanwa Kagaku Kenkyusho; non-purpose research grants from Astellas, AstraZeneca, Bayer, Boehringer Ingelheim, Chugai, Eli Lilly, Kowa, Mitsubishi Tanabe, MSD, Novo Nordisk, Ono, Taisho Toyama, and Takeda; lecturer's fees from Astellas, AstraZeneca, Bayer, Boehringer Ingelheim, Chugai, Eli Lilly, Kowa, Mitsubishi Tanabe, Mochida, MSD, Novo Nordisk, Ono, Taisho Toyama, and Takeda; advisory board for Novo Nordisk; sponsored office from Boehringer Ingelheim. T.N. reports research grants from Eli Lilly, Mitsubishi Tanabe, MSD, and Novartis; lecturer's fees from Arkray, Astellas, AstraZeneca, Boehringer Ingelheim, Eli Lilly, Johnson \& Johnson, Mitsubishi Tanabe, MSD, Novartis, Novo Nordisk, Ono, Sanofi, Sanwa Kagaku Kenkyusho, Sumitomo Dainippon, Taisho Toyama, Takeda, and Terumo. O.A. reports lecturer's fees from Abbott, Astellas, Boehringer Ingelheim, Medtronic, and St. Jude Medical. K.N. reports research grants from Actelion, Asahi Kasei, Astellas, Astellas Amgen Bio Pharma, Bayer, Boehringer Ingelheim, GlaxoSmithKline, Mitsubishi Tanabe, Novo Nordisk, Teijin, and Terumo; non-purpose research grants from Astellas, Bayer, Boehringer Ingelheim,
Bristol-Myers Squibb, Daiichi Sankyo, Eisai, Eli Lilly, Japan Lifeline, Mitsubishi Tanabe, MSD, Novartis, Novo Nordisk, Ono, Otsuka, Pfizer, Sanofi, Sumitomo Dainippon, Takeda, and Teijin; lecturer's fees from Actelion, Astellas, Astellas Amgen Bio Pharma, AstraZeneca, Bayer, Boehringer Ingelheim, Bristol-Myers Squibb, Daiichi Sankyo, Edwards Lifesciences, Eli Lilly, FUJIFILM, Fukuda Denshi, Kowa, Kyowa Hakko Kirin, Mebix, Medtronic, Mitsubishi Tanabe, Mochida, MSD, Novartis, Novo Nordisk, Ono, Otsuka, Pfizer, Roche Diagnostics, Sanofi, Sanwa Kagaku Kenkyusho, Sumitomo Dainippon, Taisho Toyama, Takeda, and Teijin; manuscript fee from Astellas, and Takeda; advisory board for Astellas, AstraZeneca, Boehringer Ingelheim, Eli Lilly, Mitsubishi Tanabe, MSD, Novo Nordisk, Pfizer, and Takeda. S.U. reports research grants from Bristol-Myers Squibb, and Kowa; non-purpose research grants from Bristol-Myers Squibb, Chugai, MSD, Pfizer, and Takeda; lecturer's fees from Boehringer Ingelheim, MSD, and Taiho; manuscript fees from Kowa; advisory board for Otsuka.

\section{Author details}

${ }^{1}$ Department of Cardiovascular, Renal and Metabolic Medicine, Sapporo Medical University School of Medicine, South 1, West 16, Sapporo 060-8543, Japan. ${ }^{2}$ Caress Sapporo Hokko Memorial Clinic, Sapporo, Japan. ${ }^{3}$ Department of Clinical Epidemiology, Hyogo College of Medicine, Nishinomiya, Japan. ${ }^{4}$ Department of Diabetes, Endocrinology and Metabolism, Fukushima Medical University, Fukushima, Japan. ${ }^{5}$ Department of Diabetes, Metabolism and Endocrinology, International University of Health and Welfare Ichikawa Hospital, Ichikawa, Japan. ${ }^{6}$ Department of Cardiology, Tomishiro Central Hospital, Tomigusuku, Japan. ${ }^{7}$ Department of Cardiovascular Medicine, Saga University, Saga, Japan. ${ }^{8}$ Department of Pharmacology and Therapeutics, University of the Ryukyus, Nishihara, Japan.

Received: 4 April 2020 Accepted: 8 June 2020

Published online: 15 June 2020

\section{References}

1. Furuhashi M. Fatty acid-binding protein 4 in cardiovascular and metabolic diseases. J Atheroscler Thromb. 2019;26(3):216-32.

2. Furuhashi M, Hotamisligil GS. Fatty acid-binding proteins: role in metabolic diseases and potential as drug targets. Nat Rev Drug Discov. 2008;7(6):489-503.

3. Hotamisligil GS, Johnson RS, Distel RJ, Ellis R, Papaioannou VE, Spiegelman BM. Uncoupling of obesity from insulin resistance through a targeted mutation in aP2, the adipocyte fatty acid binding protein. Science. 1996;274(5291):1377-9.

4. Makowski L, Boord JB, Maeda K, Babaev VR, Uysal KT, Morgan MA, Parker RA, Suttles J, Fazio S, Hotamisligil GS, et al. Lack of macrophage fatty-acidbinding protein $\mathrm{PP} 2$ protects mice deficient in apolipoprotein $\mathrm{E}$ against atherosclerosis. Nat Med. 2001;7(6):699-705.

5. Maeda K, Cao H, Kono K, Gorgun CZ, Furuhashi M, Uysal KT, Cao Q, Atsumi G, Malone H, Krishnan B, et al. Adipocyte/macrophage fatty acid binding proteins control integrated metabolic responses in obesity and diabetes. Cell Metab. 2005;1 (2):107-19.

6. Furuhashi M, Tuncman G, Gorgun CZ, Makowski L, Atsumi G, Vaillancourt E, Kono K, Babaev VR, Fazio S, Linton MF, et al. Treatment of diabetes and atherosclerosis by inhibiting fatty-acid-binding protein aP2. Nature. 2007;447(7147):959-65.

7. Cao H, Sekiya M, Ertunc ME, Burak MF, Mayers JR, White A, Inouye K, Rickey LM, Ercal BC, Furuhashi M, et al. Adipocyte lipid chaperone AP2 is a secreted adipokine regulating hepatic glucose production. Cell Metab. 2013;17(5):768-78.

8. Fuseya T, Furuhashi M, Matsumoto M, Watanabe Y, Hoshina K, Mita T, Ishimura S, Tanaka M, Miura T. Ectopic fatty acid-binding protein 4 expression in the vascular endothelium is involved in neointima formation after vascular injury. J Am Heart Assoc. 2017;6(9):e006377.

9. Cimen I, Kocaturk B, Koyuncu S, Tufanli O, Onat UI, Yildirim AD, Apaydin O, Demirsoy S, Aykut ZG, Nguyen UT, et al. Prevention of atherosclerosis by bioactive palmitoleate through suppression of organelle stress and inflammasome activation. Sci Transl Med. 2016;8(358):358ra126.

10. Mita T, Furuhashi M, Hiramitsu S, Ishii J, Hoshina K, Ishimura S, Fuseya T, Watanabe Y, Tanaka M, Ohno K, et al. FABP4 is secreted from adipocytes by adenyl cyclase-PKA- and guanylyl cyclase-PKG-dependent lipolytic mechanisms. Obesity (Silver Spring). 2015;23(2):359-67. 
11. Furuhashi M, Fuseya T, Murata M, Hoshina K, Ishimura S, Mita T, Watanabe Y, Omori A, Matsumoto M, Sugaya T, et al. Local production of fatty acid-binding protein 4 in epicardial/perivascular fat and macrophages is linked to coronary atherosclerosis. Arterioscler Thromb Vasc Biol. 2016;36(5):825-34.

12. Xu A, Wang Y, Xu JY, Stejskal D, Tam S, Zhang J, Wat NM, Wong WK, Lam KS. Adipocyte fatty acid-binding protein is a plasma biomarker closely associated with obesity and metabolic syndrome. Clin Chem. 2006;52(3):405-13.

13. Ishimura S, Furuhashi M, Watanabe Y, Hoshina K, Fuseya T, Mita T, Okazaki Y, Koyama M, Tanaka M, Akasaka H, et al. Circulating levels of fatty acidbinding protein family and metabolic phenotype in the general population. PLOS ONE. 2013:8(11):e81318.

14. Ota H, Furuhashi M, Ishimura S, Koyama M, Okazaki Y, Mita T, Fuseya T, Yamashita T, Tanaka M, Yoshida H, et al. Elevation of fatty acid-binding protein 4 is predisposed by family history of hypertension and contributes to blood pressure elevation. Am J Hypertens. 2012;25(10):1124-30.

15. Furuhashi M, Omori A, Matsumoto M, Kataoka Y, Tanaka M, Moniwa N, Ohnishi H, Yoshida H, Saitoh S, Shimamoto K, et al. Independent link between levels of proprotein convertase subtilisin/kexin type 9 and FABP4 in a general population without medication. Am J Cardiol. 2016;118(2):198-203.

16. Furuhashi M, Yuda S, Muranaka A, Kawamukai M, Matsumoto M, Tanaka M, Moniwa N, Ohnishi H, Saitoh S, Shimamoto K, et al. Circulating fatty acid-binding protein 4 concentration predicts the progression of carotid atherosclerosis in a general population without medication. Circ J. 2018:82(4):1121-9.

17. Furuhashi M, Ishimura S, Ota H, Hayashi M, Nishitani T, Tanaka M, Yoshida H, Shimamoto K, Hotamisligil GS, Miura T. Serum fatty acid-binding protein 4 is a predictor of cardiovascular events in end-stage renal disease. PLoS ONE. 2011:6(11):e27356.

18. Furuhashi M, Matsumoto M, Murase T, Nakamura T, Higashiura Y, Koyama M, Tanaka M, Moniwa N, Ohnishi H, Saitoh S, et al. Independent links between plasma xanthine oxidoreductase activity and levels of adipokines. J Diabetes Investig. 2019;10(4):1059-67.

19. Fuseya T, Furuhashi M, Yuda S, Muranaka A, Kawamukai M, Mita T, Ishimura S, Watanabe Y, Hoshina K, Tanaka M, et al. Elevation of circulating fatty acid-binding protein 4 is independently associated with left ventricular diastolic dysfunction in a general population. Cardiovasc Diabetol. 2014;13(1):126

20. Karpisek M, Stejskal D, Kotolova H, Kollar P, Janoutova G, Ochmanova R, Cizek L, Horakova D, Yahia RB, Lichnovska R, et al. Treatment with atorvastatin reduces serum adipocyte-fatty acid binding protein value in patients with hyperlipidaemia. Eur J Clin Invest. 2007;37(8):637-42.

21. Furuhashi M, Mita T, Moniwa N, Hoshina K, Ishimura S, Fuseya T, Watanabe Y, Yoshida H, Shimamoto K, Miura T. Angiotensin II receptor blockers decrease serum concentration of fatty acid-binding protein 4 in patients with hypertension. Hypertens Res. 2015;38(4):252-9.

22. Furuhashi M, Hiramitsu S, Mita T, Omori A, Fuseya T, Ishimura S, Watanabe Y, Hoshina K, Matsumoto M, Tanaka M, et al. Reduction of circulating FABP4 level by treatment with omega-3 fatty acid ethyl esters. Lipids Health Dis. 2016;15(1):5.

23. Furuhashi M, Hiramitsu S, Mita T, Fuseya T, Ishimura S, Omori A, Matsumoto M, Watanabe Y, Hoshina K, Tanaka M, et al. Reduction of serum FABP4 level by sitagliptin, a DPP-4 inhibitor, in patients with type 2 diabetes mellitus. J Lipid Res. 2015;56(12):2372-80.

24. Furuhashi M, Matsumoto M, Hiramitsu S, Omori A, Tanaka M, Moniwa N, Yoshida H, Ishii J, Miura T. Possible increase in serum FABP4 level despite adiposity reduction by canagliflozin, an SGLT2 inhibitor. PLOS ONE. 2016;11(4):e0154482.

25. Cabre A, Lazaro I, Girona J, Manzanares JM, Marimon F, Plana N, Heras M, Masana L. Fatty acid binding protein 4 is increased in metabolic syndrome and with thiazolidinedione treatment in diabetic patients. Atherosclerosis. 2007:195(1):e150-8.

26. Mori K, Tsuchiya K, Nakamura S, Miyachi Y, Shiba K, Ogawa Y, Kitamura K. Ipragliflozin-induced adipose expansion inhibits cuff-induced vascular remodeling in mice. Cardiovasc Diabetol. 2019;18(1):83.

27. Davies MJ, D'Alessio DA, Fradkin J, Kernan WN, Mathieu C, Mingrone G, Rossing P, Tsapas A, Wexler DJ, Buse JB. Management of Hyperglycemia in Type 2 Diabetes, 2018. A Consensus Report by the American Diabetes
Association (ADA) and the European Association for the Study of Diabetes (EASD). Diabetes Care. 2018;41(12):2669-701.

28. Mita T, Katakami N, Yoshii H, Onuma T, Kaneto H, Osonoi T, Shiraiwa T, Kosugi K, Umayahara Y, Yamamoto T, et al. Alogliptin, a dipeptidyl peptidase 4 inhibitor, prevents the progression of carotid atherosclerosis in patients with type 2 diabetes: the study of preventive effects of alogliptin on diabetic atherosclerosis (SPEAD-A). Diabetes Care. 2016;39(1):139-48.

29. Mita T, Katakami N, Shiraiwa T, Yoshii H, Onuma T, Kuribayashi N, Osonoi T, Kaneto H, Kosugi K, Umayahara Y, et al. Sitagliptin attenuates the progression of carotid intima-media thickening in insulin-treated patients with type 2 diabetes: the Sitagliptin Preventive Study of Intima-Media Thickness Evaluation (SPIKE): a randomized controlled trial. Diabetes Care. 2016:39(3):455-64.

30. Scirica BM, Bhatt DL, Braunwald E, Steg PG, Davidson J, Hirshberg B, Ohman P, Frederich R, Wiviott SD, Hoffman EB, et al. Saxagliptin and cardiovascular outcomes in patients with type 2 diabetes mellitus. N Engl J Med. 2013;369(14):1317-26.

31. White WB, Cannon CP, Heller SR, Nissen SE, Bergenstal RM, Bakris GL, Perez AT, Fleck PR, Mehta CR, Kupfer S, et al. Alogliptin after acute coronary syndrome in patients with type 2 diabetes. N Engl J Med. 2013;369(14):1327-35.

32. Green JB, Bethel MA, Armstrong PW, Buse JB, Engel SS, Garg J, Josse R, Kaufman KD, Koglin J, Korn S, et al. Effect of sitagliptin on cardiovascular outcomes in type 2 diabetes. N Engl J Med. 2015;373(3):232-42.

33. Rosenstock J, Perkovic V, Johansen OE, Cooper ME, Kahn SE, Marx N, Alexander JH, Pencina M, Toto RD, Wanner C, et al. Effect of linagliptin vs placebo on major cardiovascular events in adults with type 2 diabetes and high cardiovascular and renal risk: the CARMELINA randomized clinical trial. JAMA. 2019;321(1):69-79.

34. Kim YG, Han SJ, Kim DJ, Lee KW, Kim HJ. Association between sodium glucose co-transporter 2 inhibitors and a reduced risk of heart failure in patients with type 2 diabetes mellitus: a real-world nationwide population-based cohort study. Cardiovasc Diabetol. 2018;17(1):91.

35. Fisman EZ, Tenenbaum A. Antidiabetic treatment with gliptins: focus on cardiovascular effects and outcomes. Cardiovasc Diabetol. 2015;14:129.

36. Kaku K. Effects of anagliptin on serum lipids in Japanese patients with type 2 diabetes-a pooled analysis of long-term therapy with anagliptin. Jpn Pharmacol Ther. 2012;40:771-84.

37. Chiba Y, Yamakawa T, Tsuchiya H, Oba M, Suzuki D, Danno H, Takatsuka Y, Shigematsu H, Kaneshiro M, Terauchi Y. Effect of anagliptin on glycemic and lipid profile in patients with type 2 diabetes mellitus. J Clin Med Res. 2018;10(8):648-56.

38. Morimoto T, Sakuma I, Sakuma M, Tokushige A, Natsuaki M, Asahi T, Shimabukuro M, Nomiyama T, Arasaki O, Node K, et al. Randomized evaluation of anagliptin vs sitagliptin on low-density lipoproteiN cholesterol in diabetes (REASON) Trial: a 52-week, open-label, randomized clinical trial. Sci Rep. 2019;9(1):8537.

39. Ueda S, Shimabukuro M, Arasaki O, Node K, Nomiyama T, Morimoto T. Effect of anagliptin and sitagliptin on low-density lipoprotein cholesterol in type 2 diabetic patients with dyslipidemia and cardiovascular risk: rationale and study design of the REASON trial. Cardiovasc Drugs Ther. 2018;32(1):73-80.

40. Matsuo S, Imai E, Horio M, Yasuda Y, Tomita K, Nitta K, Yamagata K, Tomino Y, Yokoyama H, Hishida A, et al. Revised equations for estimated GFR from serum creatinine in Japan. Am J Kidney Dis. 2009;53(6):982-92.

41. Nabeno M, Akahoshi F, Kishida H, Miyaguchi I, Tanaka Y, Ishii S, Kadowaki T. A comparative study of the binding modes of recently launched dipeptidyl peptidase IV inhibitors in the active site. Biochem Biophys Res Commun. 2013:434(2):191-6.

42. Watanabe YS, Yasuda Y, Kojima Y, Okada S, Motoyama T, Takahashi R, Oka M. Anagliptin, a potent dipeptidyl peptidase IV inhibitor: its singlecrystal structure and enzyme interactions. J Enzyme Inhib Med Chem. 2015;30(6):981-8.

43. Yano W, Inoue N, Ito S, Itou T, Yasumura M, Yoshinaka Y, Hagita S, Goto M, Nakagawa T, Inoue K, et al. Mechanism of lipid-lowering action of the dipeptidyl peptidase-4 inhibitor, anagliptin, in low-density lipoprotein receptor-deficient mice. J Diabetes Investig. 2017;8(2):155-60.

44. Goto M, Furuta S, Yamashita S, Hashimoto H, Yano W, Inoue N, Kato N, Kaku K. Dipeptidyl peptidase 4 inhibitor anagliptin ameliorates hypercholesterolemia in hypercholesterolemic mice through inhibition of intestinal cholesterol transport. J Diabetes Investig. 2018;9(6):1261-9. 
45. Aoki K, ljima T, Kamiyama H, Kamiko K, Terauchi Y. Anagliptin decreases serum lathosterol level in patients with type 2 diabetes: a pilot study. Expert Opin Pharmacother. 2015;16(12):1749-54.

46. Chihara A, Tanaka A, Morimoto T, Sakuma M, Shimabukuro M, Nomiyama T, Arasaki O, Ueda S, Node K. Differences in lipid metabolism between anagliptin and sitagliptin in patients with type 2 diabetes on statin therapy: a secondary analysis of the REASON trial. Cardiovasc Diabetol. 2019;18(1):158.

47. Di Flaviani A, Picconi F, Di Stefano P, Giordani I, Malandrucco I, Maggio P, Palazzo P, Sgreccia F, Peraldo C, Farina F, et al. Impact of glycemic and blood pressure variability on surrogate measures of cardiovascular outcomes in type 2 diabetic patients. Diabetes Care. 2011;34(7):1605-9.

48. Apaijai N, Pintana H, Chattipakorn SC, Chattipakorn N. Effects of vildagliptin versus sitagliptin, on cardiac function, heart rate variability and mitochondrial function in obese insulin-resistant rats. Br J Pharmacol. 2013;169(5):1048-57.

49. Jiang T, Jiang D, Zhang L, Ding M, Zhou H. Anagliptin ameliorates high glucose- induced endothelial dysfunction via suppression of NLRP3 inflammasome activation mediated by SIRT1. Mol Immunol. 2019:107:54-60.

50. Li Q, Zhang M, Xuan L, Liu Y, Chen C. Anagliptin inhibits neointimal hyperplasia after balloon injury via endothelial cell-specific modulation of SOD-1/RhoA/JNK signaling in the arterial wall. Free Radic Biol Med. 2018;121:105-16.

51. Satoh-Asahara N, Sasaki Y, Wada H, Tochiya M, Iguchi A, Nakagawachi R, Odori S, Kono S, Hasegawa K, Shimatsu A. A dipeptidyl peptidase-4 inhibitor, sitagliptin, exerts anti-inflammatory effects in type 2 diabetic patients. Metabolism. 2013;62(3):347-51.

52. Makdissi A, Ghanim H, Vora M, Green K, Abuaysheh S, Chaudhuri A, Dhindsa S, Dandona P. Sitagliptin exerts an antinflammatory action. J Clin Endocrinol Metab. 2012:97(9):3333-41.

53. Masoodi M, Kuda O, Rossmeisl M, Flachs P, Kopecky J. Lipid signaling in adipose tissue: connecting inflammation \& metabolism. Biochem Biophys Acta. 2015;1851(4):503-18.

54. Burak MF, Inouye KE, White A, Lee A, Tuncman G, Calay ES, Sekiya M, Tirosh A, Eguchi K, Birrane G, et al. Development of a therapeutic monoclonal antibody that targets secreted fatty acid-binding protein aP2 to treat type 2 diabetes. Sci Transl Med. 2015;7(319):319ra205.

\section{Publisher's Note}

Springer Nature remains neutral with regard to jurisdictional claims in published maps and institutional affiliations.
Ready to submit your research? Choose BMC and benefit from:

- fast, convenient online submission

- thorough peer review by experienced researchers in your field

- rapid publication on acceptance

- support for research data, including large and complex data types

- gold Open Access which fosters wider collaboration and increased citations

- maximum visibility for your research: over $100 \mathrm{M}$ website views per year

At BMC, research is always in progress.

Learn more biomedcentral.com/submissions 